\title{
SOCIAL CONTROLS AMONG THE NATIVE PEOPLES OF THE NORTHWEST TERRITORIES IN THE PRE-CONTACT PERIOD \\ MARGARET CARSWELL*
}

\section{INTRODUCTION}

When the Europeans arrived and settled in North America, they brought the laws of their homeland with them. The legal systems they had known in Europe were adapted to the culture and conditions of the new world. The British legal traditions soon became the most widespread and today British Common Law forms the legal foundation throughout most of this continent. In the Northwest Territories our present legal system is based upon laws and legal practices which grew up and evolved over time in England.

However, legal traditions did not start in the N.W.T. with the coming of Europeans. Long before the white men arrived, the native peoples had evolved their own ways of preventing and resolving social conflict.

Today, the ancestors of these native poeple call themselves Dene and Inuit. Some of their elders still remember a time when the legal system was very different from what it is now. There were no full-time soldiers; no police, courts or jails; no designated judges; no customary or written laws.

\section{SOCIAL AND POLITICAL STRUCTURE OF THE TRADITIONAL NATIVE LIFESTYLE}

Every legal system is created as a response to the social needs of the community it serves. Because of the size and structure of traditional native communities, some components of the modern legal system such as police, courts and jails were not required to serve basic social needs.

Traditionally, both the Dene and Inuit were nomadic hunting peoples. The extremely harsh northern climate and the scarcity of food combined to make living a precarious and often-times difficult undertaking. Language and geography caused the people to band in closely knit groups of up to 50 individuals who stayed together in order to survive. Within each community each member knew one another, as each community generally consisted of two or three related or friendly families or one single extended family. There was however, some fluidity of movement between the small groups for the purpose of obtaining food.

Life could be characterized as a constant struggle to find food. The same animals that served as sustenance to the people were used to provide their clothing as well. Shelter was temporary, for the community moved continually in search of a food supply. Obviously there was little opportunity or desire to amass possessions since everything had to be carried when the group moved.

* The author is a resident of Yellowknife and is a member of both the Alberta and the Northwest Territories Bars. 
A very basic political organization reflected this simple lifestyle. The size of the bands permitted consensual decision-making and it was rare to have a recognized leader. ${ }^{1}$

In general, leaders were men or women of proven wisdom and skill, and the group followed their decisions. Often one man would be the leader during a communal hunt, another during a fight with enemies, and still another during a long sledge or canoe journey. Some people were all-around leaders who stood out because of their strength, wisdom and skill in magic. Such a person might become the main chief of a band or a whole tribe, but even then his followers could disagree or just move away to live elsewhere. Although most of the leaders were men, women of strong character sometimes had power over a band or tribe.

Each person within the community had his own position and appointed tasks. The concepts of sharing and cooperation were strongly emphasized. A given individual might be respected because of certain perceived abilities, but no one occupied a position of status which could be termed primarily political or legal in nature.

\section{PREVENTION OF SOCIAL CONFLICT}

Both the Dene and Inuit used similar means to prevent conflicts from arising within the community. As they had no written language they had no written laws. Instead, myths and stories describing taboos were an effective way of conveying acceptable and unacceptable social behaviour. These stories were passed on from one generation to the next as part of the oral traditions of the community. They often focussed on malefemale roles and on the roles of each family member. They emphasized the obligation of sharing work, food, and material possessions along with the values of cooperation and mutual aid and assistance among family members.

Importance was given to a form of partnership whereby unrelated persons would become friends and swear to defend each other and even avenge the others death in case of murder. These partnerships were found to have occurred both where the partners spoke the same language and also where the parties were from a different trading group.

Finally, there was the power of shamans to control behaviour through fear of death or disease. A medicine man could affect the community in positive or negative ways as evil sorcerers who disrupted the essential harmony of the camp were known to suffer death as a result.

Overall, the single overriding consideration among the Dene and Inuit was maintenance of the peace, order and general equilibrium of the community. Nothing was allowed to interfere with it.

\section{CONFLICT RESOLUTION}

The traditional system of social control did not aim at justice but rather at restoring peace within the community. There was no structured system of punishment, according to the wrong committed. Typically, the community decided by consensus the type of punishment in each in-

1. K. Crowe, The History of the Original Peoples of Northern Canada (1974) 34. 
dividual case which would best serve to restore the community to its usual harmonious state. ${ }^{2}$

On this basis, the settlement may combine in killing a man now suspected of witchcraft, for such persons are a menace to the peace of the society. The killing is now however a punishment for the practising of witchcraft, for the society may, in the same manner, get rid of a man with a wild and brutal temperament or of old or sick people who are a burden upon the settlement.

\section{A. MINOR CONFLICTS}

Within the small bands of Dene and Inuit, the most common causes of conflict and tension arose from situations of mockery, jealousy, laziness or minor misunderstandings. Sometimes the conflict would remain local as between two or three members of the group, while at other times, the conflict would be serious enough to affect the whole community.

Within a small group of people who all knew one another the power of public opinion was overwhelming. The troublemaker could be subjected to gossip, social criticism and ridicule. The rest of the community might decide to ignore the deviant person until he rectified his behaviour. Sometimes the other members would withdraw their support and assistance to the non-conforming person, letting him fend for himself.

Where the troublemaker directed his hostilities toward one person in particular, boxing and wrestling matches were available to deal with the tension. These became institutionalized methods of resolving conflict, performing the same function as modern-day civil courts. Anthropologists Graburn and Strong indicate that such boxing contests were a form of $:^{3}$

usually nonfatal competition . . . in which two men who disliked each other or merely competed for prestige took turns in hitting each other as hard as they could on the side of the head. The last man standing won, and thus gained both the prestige of the social group and implicitly the judgement that his view was justified in the quarrel.

Another social control mechanism was derisive songs, or song duels. Graburn explains that ${ }^{4}$

two people with a disagreement or quarrel would be encouraged to make up insulting songs about each other and perform these in front of the rest of the group; the rest of the community would then choose the winner.

In the following example, the first singer, Kilime, complains that the second singer, Equerqo, has stolen his wife.

Kilime sings: ${ }^{5}$

2. K. Birket-Smith, Eskimos (1976) 164.

3. N. Graburn and S. Strong, Circumpolar Peoples: An Anthropological Perspective (1969) 165.

4. Id. p. 165.

5. K. Rasmussen, Eskimo Poems From Canada and Greenland (1973) 75. 
Eqerqo replies:

\author{
Let me cleave words \\ sharp little words, \\ like the fire-wood \\ that I split with my axe! \\ A song of old times, \\ a gust of soul from ancestors, \\ a song of oblivion for my wife, \\ a song to soothe the longing \\ overwhelming me! \\ This loud-mouth's \\ ravished her, belittled her: \\ a wretched cannibal \\ who loves to eat men's flesh \\ in times of scarcity!
}

Shameless impudence!
Half-hearted coward!
You want to put the blame on me
and scare me, with your mockery?
But l'm indifferent
to the risk of being killed.
Look: it's my wife that you sing about.
She was yours once,
but you weren't quite so loving
at the time.
When she was all alone,
you never praised her
in your fighting challenge-songs.
Now she's mine
and won't go visiting
false lovers, womanisers,
singing beautifully
in strange tents.

\section{B. MAJOR CONFLICTS}

In all societies some acts are of such a serious nature as to affect the well-being of the entire community. Which deviant behaviour will disrupt the community varies however, from one culture to the next. For the traditional Dene and Inuit, the most frequent breaches of the peace centered about the competition for women. The abduction of a wife could lead to assault, attempted or even successful murder. Sorcery and witchcraft were the only other types of behaviour that could affect a native community so deeply.

Competition for women arose because the Dene and Inuit were nomadic hunting peoples. The hunters were always male. The better the hunter, the more food he could catch; the more food he could catch the more people that could be fed and the more women and children he could maintain. The more women and children he maintained, the greater was his prestige. It was a mark of tremendous prestige to be able to support more than one wife. Every man needed at least one wife if he were to survive as the women prepared the food for eating. They also prepared the animal skins and made them into clothing. Consequently, there was competition for women, both out of necessity and for prestige. Furthermore with so few poeple in each band, there was a constant need for new blood. This was achieved by stealing women from other bands.

The kidnapping of a wife was generally not tolerated. If the wife were kidnapped by non-band members the usual revenge was warfare. 


\section{Historian Keith Crowe writes that ${ }^{6}$}

warfare among the northern peoples was common, but seasonal and small scale. It usually consisted of surprise attacks rather than all-out battles and it included many actions of crime and punishment which modern society would deal with by police, courts and jails.

As an aggressive measure, warfare was used to abduct women. Attacks on outside communities were also known to have occurred in order to avenge bodily assaults, witchcraft, hunting on another's territory or murder.

Within the individual community, several different measures were available to resolve or punish unacceptable behaviour. The community would usually decide by consensus what appropriate action should be taken. Ostracism and death were the two most common measures.

If the group decided that the wrongdoer had to be ostracized, the community could either break camp and abandon the troublemaker or they could force the wrongdoer to leave the group, in exile. Persistent violation of taboos, excessive bullying and wife-stealing were deviant acts which were punished by ostracism.

Where a more serious measure had to be taken to restore order the community could decide that an individual had to be put to death. Capital punishment was an unknown concept to the traditional Dene and Inuit. Death was not inflicted in order to punish a wrongdoer or to deter others. However, where a person had created a burden on the community, either because he disrupted the harmony of the group or because he did not perform his designated duties, he was eliminated. Thus, some infants (especially female), invalids, elderly and chronically ill people were put to death (or left to die) for the same reasons as were murderers or evil sorcerers.

Because there existed no concept of crime and punishment, what one man viewed as an execution could be seen by the family of the dead person as murder. To avoid vengeance, the whole community in conjunction with the wrongdoer's family, would meet to decide the perpetrator's fate. If the community decided that the man had to be put to death, close relatives of the of fender would then act as executioner.

In the traditional Dene and Inuit communities, death by execution is known to have occurred where the wrongdoer committed successive murders, was excessively belligerent or obnoxious, was an evil sorcerer, a chronic liar or was insane.

\section{COMPARISON OF SYSTEMS}

In modern society, we have a system of moral values and rules of living that we are taught in our childhood. In addition, we have a set of written prohibitions called criminal laws. If, as adults, we contravene a criminal law we are subject to a predetermined punishment.

Traditional Dene and Inuit society also inculcated its young with moral values however the small native bands never experienced the need to create crimes. Any act which disrupted the community would be dealt with on an ad hoc basis. Because the severity of the effect of the disrup- 
tive behaviour would vary according to many other extraneous circumstances, there was never a need or desire to relate any particular disruptive act to a set punishment. Also these small groups never experienced the volume of deviant behaviour that we know today. Theft and property crimes were not prevalent because there was little to damage or steal. And with only a few people in each band, violence to the person was rare as well.

Today when someone suspects that a crime has been committed, the police are called in to investigate. In traditional times, the whole community would have taken on the police function. If the police find a suspect, that person is tried in court and, if found guilty, is sentenced according to law. Traditional native communities would have decided by consensus what appropriate action should be taken. The remedy decided upon would have correlated to the degree of disruption the deviant act produced in the community on that particular occasion. In modern society the punishment is designed (in theory at least), to meet the crime regardless of the effect that particular behaviour creates in other people. From this comes our concept of justice, which was non-existent in traditional societies.

Today, the punishment for committing a crime is usually a jail sentence. In this way a criminal is ostracized from the community. We differ from the traditional approach as we continue to provide this person with a minimum of care. The native way was to let nature take its course. Both legal systems resort to death as the ultimate tool of social control. While we reserve capital punishment for those convicted of the most heinous crimes, the Dene and Inuit used it to eliminate those whose burden on the community was too great.

\section{CONCLUSION}

Nature was the great enemy of the Dene and Inuit. Their lives were characterized by the struggle to survive. Today, we live in larger, more complex units. We are better able to combat and domesticate nature. We pay for that in the complexity of our lifestyles. Our laws and legal system reflect our lifestyles just as traditional Native methods of coping with social conflict reflect the way they lived. 